\title{
Bullies in White: The Reality of Incivility in Nursing
}

\author{
Tennille Buck-Hooper ${ }^{1}$ \\ ${ }^{1}$ Nurse Educator/Staff Development, Kalamazoo Psychiatric Hospital, Kalamazoo, Michigan, USA \\ Correspondence: Dr. Sam Abraham, Associate Professor of Nursing, Bethel College School of Nursing, 1001 \\ Bethel Circle, Mishawaka, Indiana, 46545, USA.
}

Received: January 12, 2018

Accepted: January 29, 2018

Online Published: January 31, 2018

doi:10.20849/ijsn.v3i1.300

URL: https://doi.org/10.20849/ijsn.v3i1.300

\begin{abstract}
Incivility, bullying, horizontal, vertical, and lateral violence are unethical behaviors. This affects job satisfaction, retention, and causes added stress. The purpose of this article is to provide information relative to key descriptions of incivility, discuss its impact on nurses and patient care, and lastly to discuss ways to reduce incivility in the workplace and nursing as a whole. The phrase, nurses eat their young, was commonly used in the past. Bullies in white refer to intentional maltreatment of the nurses, by the nurses. It is reported that more than one-third of nurses leave their employment, costing the healthcare industry billions of dollars annually because of incivility.
\end{abstract}

Keywords: incivility, bullying and nurses, horizontal, vertical, and lateral violence

\section{Introduction}

Nurses are ethically obligated to create a culture of civility. In 2015, because of the reports indicating that patient safety was compromised as a result of incivility in nursing, the American Nurses Association's (ANA) Code of Ethics for Nurses with Interpretive Statements indicated that nurses are required to "create an ethical environment and culture of civility and kindness, treating colleagues, co-workers, employees, students, and others with dignity and respect" (ANA, 2015, p. 1). In nursing school, the professors warned, nurses eat their young. This statement was intended to elude that adversity in nursing is a fact and it was the instructor's way of saying to plan for what is deemed the inevitable. This seemed like a terrible introduction to nursing, and if true, an awful practice to exist. Progressing through nursing school, one will find that nursing students are quite competitive, instructors have an air of impermeability, and being on ones A-game was expected. Coursework will soon get underway and then the entry into the clinical setting. It is then that one realizes the questions regarding what professors had warned about nursing. It will become painfully evident that some nurses really do eat their young and siblings too! The purpose of this article is to provide information relative to key descriptions of incivility, discuss its impact on nurses and patient care, and lastly to discuss ways to reduce incivility in the workplace and nursing as a whole.

\section{Definition}

Incivility is low-intensity divergent conduct with ambiguous intent to harm others. Bullying is the intentional mistreatment that targets particular individuals. Meilaender (2013) stated that nurses treat other nurses in hurtful ways and refers to this behavior as horizontal violence. Horizontal violence is synonymous with workplace bullying. Ostrofsky (2012) alleged workplace incivility differs from workplace violence in that workplace incivility is a behavior that everyone has experienced, witnessed, or engaged in sometime during their careers. Meilaender (2013) described horizontal incivility at work as having the characteristics such as raising eyebrows, eye rolling, giving a cold shoulder, sarcasm, rudeness, making snide remarks, sabotaging, undermining, withholding support or needed information, passive aggressive behavior, gossiping, blaming, scapegoating, and spreading false accusations. Incivility can also be carried out by not respecting, name-calling, attacking a person's integrity, rude behavior, disregarding professional input about patient care, persistent hostility, and consistent verbal attacks.

\section{Methodology and Literature Review}

\subsection{Databases}

The literature review was performed with thorough exploration and investigation using the Cumulative Index of 
Nursing and Allied Health Literature, PubMed, and Ovid databases. Using the search terms incivility; bullying and nurses; horizontal, vertical, and lateral violence some peer-reviewed, scholarly journal articles were readily available. The literature chosen for review were published from 2012-2016, meticulously analyzed, and methodically pieced for proper evidence-based review.

\subsection{Causes of Incivility in Nursing}

It is important to recognize that there are causes for incivility because of stressors inherent to nursing but it is equally important to recognize that some nurses, like others in any profession, are just plain mean. Blevins (2015) alleged, individuals who engage in acts of incivility often exhibit poor self- esteem, have poor social skills, are abusive, and lack self-restraint. Meilaender (2013) claimed that the Tall Poppy Syndrome is a type of behavior in nursing that casts shade on those who are individually successful by those who are in the same profession. These are individuals who will engage in behaviors, which are aimed to bring down other nurses who are perceived as someone who may be achieving or who are more successful.

An example of a victim of the Tall Poppy Syndrome is if one secures a sought-after position or promotion and excel at it when established nurses who applied for it did not get the job. Therefore, they may take every opportunity to seek out or point out perceived shortcomings of the promoted employee. Those who witness these behaviors may state that the nurse was envious. Regardless of the reason, it may make the victim feel anxious at times.

Nursing could be likened to that of an abused individual becoming a perpetrator of abuse of some kind because of the abuse they endured. Mikaelian and Stanley (2016) presented an interesting take on incivility aside in nursing in relation to the history of the nurse in the medical field where nurses as having an oppressed past. The disposition of nurses was viewed as one that was under the helm of the doctors, which has historically been a strenuous relationship, and a struggle for respect. The oppression of nurses by physicians, in turn, affected their peers or subordinates.

Carr, Pitt, Perrell, and Recchia (2016) discussed incivility in student nurses, highlighting that incivility can be quiet, and therefore more difficult to address. It is important to identify the potential cause for behavior and figure out a way to improve. Getting to the root of the problem may be challenging because of the covert and passive-aggressive nature of those engaging in incivility. Part of the solution involves educating in depth, early in the nursing schools, creating and implementing zero tolerance, and enforcing the code of professional conduct. It is important to discuss terms and case studies regarding incivility, horizontal/lateral/vertical bullying, civility, collegiality as a part of the curriculum for student nurses so that they can know what those terms mean and be better equipped to address the negatives and support the positives upon entering the workforce. Role-play amongst students during nursing theory would allow for students to experience and understand the effects of incivility on peers as nursing students and as nurses. Mikaelian and Stanley (2016) supported the school of thought when they stated the issue should be addressed at the beginning of a nurse's education. It is important to reiterate that to simply state that nurses eat their young, or reading the ANA code of ethics are not enough to suffice when it comes to nurses truly comprehending the length at which incivility can go in decimating ones' spirit in nursing.

\subsection{Effects of Incivility on Nurses}

The impact of incivility could be increased turnover, increased medical errors, increased stress, burnout, emotional exhaustion, and poor patient outcomes. This behavior could lead to a lasting negative impression on other nurses. Meilaender (2013) stated that traumatized nurses would function as the walking wounded when the stress caused by adverse working conditions are not dealt with appropriately. The problem with incivility is that not only are nurses wounded but patients are also at risk for mistreatment, disrespect, and disadvantaged care. Therefore, it is important for each nurse to take responsibility for themselves, and hold others accountable to protect and heal those already wounded.

Ostrofsky (2012) highlighted the different pairings of incivility: management may be guilty of bullying a nurse. New nurses complain that they are given unfavorable assignments, or are mandated more often than others are regardless of seniority or frequency. They claim that their requests are often ignored. A nurse, who may be bullied by a peer, may, in turn, bully a patient. The results of negativity in the work environment because of incivility is a lowered self-esteem, damaged relationships, decreased morale, increased stress, and increased turnover rates which this is said to impact the organization's bottom line (Ostrofsky, 2012).

\subsection{Impact of Incivility on Patient Care}

Meilaender (2013) says, "Safeguarding patients and patient care is a priority, and positive nurse-nurse 
relationships promote the moral climate necessary for safe, competent care" (p. 107). Nursing is a very challenging and demanding profession, where one's intellectual and emotional self must work in synchrony to provide competent and compassionate care. When the work environment is polluted with negativity, it makes the job of providing quality care challenging.

Blevins (2015) noted a direct connection of incivility to medication safety, stating that nurses often failed to report errors because they feared being gossiped about or receive some punishment. It is often difficult for nurses, especially new nurses to seek assistance in practice because their assigned preceptor engages in workplace incivility. Sometimes the thought is that a nurse is a nurse and they should already know everything there is to know about a job. Nurses do not always like to train other nurses, so when assigned a new employee they are not always pleasant or helpful. Lachman (2015) stated that $40 \%$ of clinicians who may have needed help with patient care events kept quiet rather than ask a question of a known intimidator. This should never be the norm. Placing a patient at risk because nurse-to-nurse relationships are strained is a very serious safety issue.

\subsection{Effect of Incivility on the Nursing Shortage}

Olubunmi, Hanson, O'Connor, and Dunn (2013) shared; in 2010, the ANA report indicated that $53 \%$ of nurses were considering leaving their positions. Mikaelian and Stanley (2016) stated that the global nurse workforce will undergo "unprecedented shortfalls," and that the forces of incivility in nurses compounds this shortage because workplace bullying in nursing is pushing nurses out of the nursing profession. The issue with incivility is that it is often difficult to identify, and is covert in nature. The incidence of incivility is under-reported because victims fear that management will not support them. Blevins (2015) reported that $37 \%$ of nurses leave their employment, costing the health industry $\$ 300$ billion dollars annually because of incivility.

\subsection{Reducing the Incidence of Incivility}

Nurses must refuse to take part in acts of incivility. Organizational leaders must institute a zero-tolerance policy for uncivil behavior. Managers must lead by example, thus creating authentic leadership. Khadjehturian (2012) said, "Nurses must consciously decide to stop this destructive conduct before it destroys nursing" (p. 639). Much of the change that is necessary involves a conscious effort on the part of the nurse. The culture within the organization in which the nurse works must also change because of the sheer power peer influence plays in shaping what is accepted in the workplace.

Olubunmi et al. (2013) observed, creating a civil work environment calls for better interpersonal skills that involve nurses refusing to take part in acts of incivility, and being intolerant of rude behaviors. The dance of civility is an attitude that fosters apologizing for and refusing to engage in behaviors setting the standard for others to follow suit.

The principle of virtue ethics involves an individual assessing how they should be in relation to doing good. Placing value in positive relations with peers in nursing is important because it allows for acceptance of another person's strengths, an appreciation of their abilities and an opportunity not to reflect on others inability to meet expectations placed on them. Addressing incivility and culture that normalize the behaviors, is likened to treating disease in the body, in that the identification of the root cause of the illness must be considered to obtain success. The difficult thing about incivility is that is often passive-aggressive in nature. Incivility is not easily recognized and like a tree, it is deeply rooted in the culture of organizations, making it difficult to correct.

Nurses must reduce the incidence of incivility by responding to disrespectful behavior in a civil manner, cognitive rehearsal, and scripting. Learn to identify the behavior, document facts, and be specific. If someone is yelling, you want to respond: "I'll be willing to continue this conversation when you are not yelling." If someone makes a rude comment, you want to respond: "I'm offended by the rude comment."

\section{Conclusion}

Incivility, bullying, horizontal, vertical, and lateral violence are unethical behaviors. This affects job satisfaction, retention, and causes added stress. It is the nurse's responsibility to behave professionally and not engage in such behaviors. Nurse Managers must create a strategy of civility norms that foster healthy working conditions.

Not enough can be said regarding the importance of modeling positive behavior and setting a level of expectation for respect of others. Education is imperative in the fight to reduce and eliminate incivility in nursing by educating about incivility in a meaningful way. The more people know about incivility and its identification, reduction and elimination can occur much sooner. Positive behavior should exist in the classroom, the labs, and clinical sites well into the time that new nurse's transition into independent practice and beyond. Examples of real life experiences should be shared by those teaching and mentoring in the schools of nursing and the code of conduct embraced and enacted throughout the curriculum for reinforcement of the ethical principle of 
benevolence. The message regarding the intolerance of incivility must be clear and enveloped within a culture as well as fostered and promoted by those in healthcare leadership. The statement and practice of nurses eating their young should no longer be the expected culture of nursing but rather a culture that embraces an ideology that nurses nurture their young.

\section{References}

American Nurses Association ([ANA], 2015). New Position Statement: Incivility, Bullying, and Workplace Violence. http://www.nursingworld.org/incivilitybullying-and-workplaceviolence-positionstatement

Blevins, S. (2015). Impact of incivility in nursing. MEDSURG Nursing, 24(6), 379-380. Retrieved from https://www.ncbi.nlm.nih.gov/pubmed/26863699

Carr, J., Pitt, M., Perrell, E., \& Recchia, N. (2016). Mentoring students: Exploring and managing incivil behaviour in community nursing placements. British Journal of Community Nursing, 21(4), 203-207. https://doi.org/10.12968/bjen.2016.21.4.203

Khadjehturian, R.E. (2012). Stopping the culture of workplace incivility in nursing. Clinical Journal of Oncology Nursing, 16(6), 638-639. https://doi.org/10.1188/12.CJON.638-639

Lachman, V.D. (2015). Ethical issues in the disruptive behaviors of incivility, bullying, and horizontal/lateral violence. Urologic Nursing, 35(1), 39-42. Retrieved from www.medscape.com/viewarticle/84114

Meilaender, G. (2013). Bioethics: A primer for Christians (3rd ed.) (pp. 106-107). Grand Rapids, MI: Eerdmans.

Mikaelian, B., \& Stanley, D. (2016). Incivility in nursing: From roots to repair. Journal of Nursing Management, 24(7), 962-969. https://doi.org/10.1111/jonm.12403

Olubunmi, O., Hanson, P., O’Connor, N., \& Dunn, D. (2013). Relationship of workplace incivility, stress, and burnout on nurses' turnover intentions and psychological empowerment. The Journal of Nursing Administration, 43(10), 536-542. https://doi.org/10.1097/NNA.0b013e3182a3e8c9

Ostrofsky, D. (2012). Incivility and the nurse leader. Nursing Management, 43(12), 18-22. https://doi.org/10.1097/01.NUMA.0000422892.06958.51

\section{Copyrights}

Copyright for this article is retained by the author(s), with first publication rights granted to the journal.

This is an open-access article distributed under the terms and conditions of the Creative Commons Attribution license (http://creativecommons.org/licenses/by/4.0/). 